\title{
Procesos organizativos de mujeres y víctimas del conflicto armado y sus relaciones con la democracia local en el Oriente Antioqueño*
}

\author{
Diana Hoyos GÓMEZ** \\ ANGÉLICA NiETo GARCíA***
}

Archivo recibido: 9 de octubre de 2015.

Archivo aprobado: 26 de agosto de 2016.

Doi: http://10.12804/revistas.urosario.edu.co/desafios/a.4484

Para citar este artículo: Hoyos, D., \& Nieto García, A. (2017). Procesos organizativos de mujeres y víctimas del conflicto armado y relaciones con la democracia local en el Oriente Antioqueño. Desafíos, 29(1), 139-175. Doi: http://10.12804/revistas.urosario.edu.co/desafios/a.4484

\section{Resumen}

El articulo examina procesos organizativos de mijeres y victimas del conflicto armado en el Oriente Antioqueño en aras de analizar sus relaciones con los discursos y expresiones de la democracia local. Para esto se toman como puntos de partida los

* Esta investigación fue desarrollada en el marco del proyecto "Acción Colectiva y Élites Políticas en el Ámbito Local. Una Perspectiva Comparada sobre Algunos Procesos de Democratización en Colombia y México", financiado por el Fondo de Investigaciones de la Universidad del Rosario (FIUR).

** Antropóloga y Politóloga. Magíster en Antropología, University of Pittsburgh, y Magíster en Estudios Políticos, Universidad Nacional de Colombia. Actualmente, la autora cursa sus estudios doctorales en Antropología en la Universidad de Pittsburgh. Correo electrónico: drh65@pitt.edu. ORCID: http://orcid.org/0000-0003-1589-584X

*** Politóloga. Magíster en Estudios Políticos de la Universidad Nacional de Colombia. Investigadora del Centro de Pensamiento Humano y Social (CPHS) de la Corporación Universitaria Minuto de Dios y profesora de cátedra de la Universidad del Rosario. Correo electrónico: angelicanietog@gmail.com. ORCID: http://orcid.org/0000-0002-3628-2420 
significados que estas organizaciones le atribuyen a la democracia. En el documento se proponen que estas relaciones pueden ser analizadas en dos direcciones. Por un lado, estos procesos organizativos han apropiado y redefinido los discursos institucionales de ciudadania y participación, y han buscado encontrar apoyos e interactuar con las instituciones en la esfera política formal, como una estrategia para que sus voces sean escuchadas y posicionar sus reivindicaciones en el espacio de lo público. De otro lado, se evidencia una apropiación de los discursos sobre la ciudadanía y la participación por parte de estas organizaciones para incidiry tener un impacto en la cotidianidad, en un contexto que ha sido fuertemente afectado por la violencia política. Los procesos organizativos en los que se centra este artículo son la experiencia de la Asociación Provincial de Victimas a Ciudadanas, el Centro de Acercamiento para la Reconciliación y Reparación, y la Asociación de Mujeres del Oriente Antioqueño. Palabras clave: Democracia, procesos organizativos de víctimas y mujeres, ciudadanía y participación.

\title{
Organizational Processes of Women and Victims of Armed Conflict and their Relationship with Local Democracy in Eastern Antioquia
}

\begin{abstract}
This paper examines organizational processes promoted by women and victims of armed conflict in the Eastern Antioquia region of Colombia in order to analyze the relationship between these processes and the discourses and expressions of local democracy. The research focuses on the meanings that democracy takes for these organizations. The paper analyzes these relationships in two different ways. On the one hand, organizational processes have appropriated and redefined the institutional discourses of citizenship and participation as well as interacted with institutions in order for women and victims to be listened to and to make their claims visible in the public arena. On the other hand, these organizations have appropriated discourses on citizenship and participation in order to infuence everyday life in a context deeply affected by political violence. The organizational processes examined here are the Asociación Provincial de Victimas a Ciudadanas, Centro de Acercamiento para la Reconciliación y Reparación, and Asociación de Mujeres del Oriente Antioqueño.
\end{abstract}


Keywords: Democracy, organizational processes of victims and women, citizenship, participation.

\title{
Processos organizativos de mulheres e vítimas do conflito armado e relações com a democracia local no Oriente Antioqueño
}

\begin{abstract}
Resumo
O artigo examina processos organizativos de mulheres e vitimas do conflito armado no Oriente Antioqueño em favor de analisar as suas relações com os discursos e expressões da democracia local. Para isto tomam-se como pontos de partida os significados que estas organizações the atribuem à democracia. No documento propõem-se que estas relacões podem ser analisadas em duas direções. Por um lado, estes processos organizativos têm apropriado e redefinido os discursos institucionais de cidadania e participação, e têm buscado encontrar apoios e interatuar com as instituições na esfera política formal, como uma estratégia para que as suas vozes sejam ouvidas e posicionar as suas reivindicações no espaço do público. Pelo outro lado, evidencia-se uma apropriação dos discursos sobe a cidadania e a participação por parte destas organizações para incidir e ter um impacto na cotidianidade, em um contexto que tem sido fortemente afetado pela violência política. Os processos organizativos nos que se centra este artigo são a experiência da Associação Provincial de Vitimas a Cidadãs, o Centro de Aproximação para a Reconciliação e Reparação, e a Associação de Mulheres do Oriente Antioqueño.
\end{abstract}

Palavras-chave: Democracia, processos organizativos de vitimas e mulheres, cidadania e participação.

\section{Introducción}

Este artículo busca dar cuenta de algunos procesos organizativos promovidos por víctimas del conflicto armado en el Oriente Antioqueño, así como su relación con discursos y expresiones de la democracia local en esta región. Específicamente, nos centramos en la experiencia de la Asociación Provincial de Víctimas a Ciudadanas 
(Aproviaci) y del Centro de Acercamiento para la Reconciliación y Reparación (CARE) del municipio de San Carlos.

Los procesos organizativos de víctimas en la región no pueden ser entendidos de manera desligada de lo que ha sido la organización de las mujeres en el Oriente Antioqueño y de su proceso de empoderamiento social y político. ${ }^{1}$ Estos procesos organizativos de víctimas empiezan a adquirir visibilidad en el contexto del escalamiento del conflicto armado en la región y se consolidan en el periodo que sigue a la aprobación de la Ley de Justicia y Paz.

En el documento se propone que las relaciones de los procesos organizativos de víctimas y de mujeres en el Oriente Antioqueño, y los discursos y expresiones de la democracia local se han articulado fundamentalmente en dos direcciones. Por un lado, estos procesos organizativos han buscado apropiar y redefinir los discursos institucionales de ciudadanía y participación, así como encontrar apoyos e interactuar con las instituciones en la esfera política formal como una estrategia para que sus voces sean escuchadas y para posicionar sus reivindicaciones en el espacio de lo público. Esta relación no se limita únicamente a lo estratégico, sino que involucra una apuesta de estas organizaciones por la democracia y la apropiación de sus discursos.

De otra parte, la relación con la democracia involucra la apropiación de los discursos de ciudadanía y participación por parte de las organizaciones de mujeres y víctimas no solo con el propósito de incidir en la esfera política formal, sino tener un impacto en la vida cotidiana en un contexto que ha sido profundamente afectado por el conflicto armado. En este contexto, las mujeres y en particular las víctimas han articulado múltiples estrategias y se han organizado para responder a los efectos del conflicto armado en la vida familiar y en las comunidades. Estas estrategias han incluido la formación de lideresas comunitarias, que han jugado un papel importante en la elaboración del duelo y la construcción de alternativas en medio

\footnotetext{
1 Debido a esto, aunque este artículo se enfoca particularmente en el proceso organizativo de víctimas, también examinamos con detalle el proceso organizativo de mujeres.
} 
de la guerra y la reconstrucción del tejido social, así como acciones de resistencia no violenta, como movilizaciones, jornadas de la luz y otros actos simbólicos.

El presente artículo está dividido en cinco partes. En la primera se presentan algunas precisiones teóricas y metodológicas y se aborda lo relativo a la relevancia de este estudio. En la segunda sección se presenta rápidamente la contextualización de las dinámicas relacionadas con la presencia de los actores armados en la región del Oriente Antioqueño. La tercera parte examina los procesos organizativos que se han producido en la región desde los noventa y sus antecedentes, así como las relaciones que se han dado entre las organizaciones de mujeres, los procesos de formación política y ciudadana que han tenido lugar y las organizaciones de víctimas. La cuarta parte aborda lo relativo a las relaciones que se han dado entre estos procesos organizativos y los discursos y prácticas de la democracia local. Para ello nos centramos en las miradas de estas organizaciones sobre los conceptos de ciudadanía, participación y reconciliación, y en las articulaciones y expresiones en la vida cotidiana de estas mujeres y víctimas. Por último, proponemos algunos elementos de análisis que examinan las relaciones entre estos procesos organizativos y sus acciones para incidir en los espacios de decisión pública.

\section{Precisiones teóricas y metodológicas}

En este artículo no tomamos como punto de partida una definición predeterminada de democracia, sino que hacemos referencia a ella desde los propios significados que le atribuyen los actores con los que trabajamos, en este caso, las organizaciones de víctimas y de mujeres en las que se centró el presente trabajo. Este artículo sigue la propuesta de Julia Paley (2008), quien sostiene que en vez de partir de nociones preconcebidas de democracia su complejidad requiere nuevas formas de entendimiento. De acuerdo con Paley, es importante "detectar las distintas variaciones asociadas con el término democracia" en diversos contextos, así como entender "cómo la democracia es conceptualizada en el discurso público y en la práctica” (Paley, 2008, p. 5). Desde esta 
mirada, el análisis de la democracia no se centra exclusivamente en su significado o en su práctica, sino que presta atención a la intersección entre estas dos dimensiones de análisis.

Esta postura contrasta con otras aproximaciones que ponen énfasis en aspectos como la competencia o la participación como elementos definitorios de la democracia o que permiten evaluar su funcionamiento, así como con aquellas que se enfocan en una serie de características y procedimientos que le son necesarios como, por ejemplo, la celebración imparcial de elecciones, el respeto de las libertades civiles y políticas, la existencia y el respeto a la oposición política y la inclusión sociopolítica, etc. El propósito de este artículo no es evaluar la democracia desde una serie de criterios preestablecidos o enfocándose en unas dimensiones que se consideran relevantes en términos conceptuales o normativos, más bien, busca examinar de qué manera los procesos organizativos de víctimas y de mujeres en el Oriente Antioqueño se relacionan con discursos y expresiones de la democracia local. Para esto privilegiamos los discursos y los significados sobre la democracia enunciados por los actores que estudiamos.

En el marco de los significados que asume la democracia para las organizaciones de víctimas y mujeres, la relación con la dimensión más institucional y la esfera política formal, desde la que la democracia es comúnmente pensada, aparece en el discurso de estas organizaciones y en sus prácticas. Esto incluye no solo los discursos institucionales sobre ciudadanía y participación que han sido apropiados y redefinidos por estas mujeres, sino la interlocución con las instituciones y la búsqueda por incidir en los espacios de decisión política para posicionar sus reivindicaciones. Sin embargo, la democracia no solo se entiende desde esta mirada. La democracia local y, específicamente, la democracia participativa adquieren un significado para las organizaciones de víctimas y de mujeres que está ligado a su cotidianidad $y$, en particular, a los efectos de la guerra en sus vidas, a su capacidad para responder colectivamente a estos efectos y a los procesos de reconstrucción del tejido social promovidos por estas organizaciones. 
$\mathrm{Al}$ enfocarse en las relaciones entre las organizaciones de víctimas y de mujeres y la democracia local, y tomando como punto de partida los significados que los miembros de estas organizaciones le atribuyen a la democracia, este estudio nos permite centrarnos en la manera como esta se manifiesta en el nivel micro y cómo se construye desde abajo, en este caso, en relación con y desde la mirada y las acciones de las mujeres que hacen parte de los procesos organizativos. Así mismo, nos permite enfocarnos en la conceptualización que de la democracia hacen los actores que participan en ella y en los discursos que sobre ella circulan o se construyen y redefinen en el nivel micro.

Algunos estudios han prestado atención al tema de los discursos de la democracia y sus significados (Paley, 2002, 2008; Ong, 1999; Verdery, 1996; Coronil, 1997), mostrando no solo la variación de significados que puede asumir en distintos contextos, sino también cómo los significados del término democracia son disputados entre grupos "con intereses en diferentes resultados" y entre quienes están vinculados entre sí bajo "relaciones de poder desiguales" (Paley, 2002, p. 476). Este artículo se inscribe en esta línea de estudios al abordar los significados que la democracia local asume para las organizaciones de víctimas y de mujeres, y al privilegiar la manera como esta se construye en el nivel micro (Albert, 2016), pero se enfoca en un contexto que ha sido fuertemente afectado por el conflicto armado y la violencia.

En consonancia con lo anterior, es importante considerar que los procesos organizativos de víctimas y de mujeres en el Oriente Antioqueño han tenido lugar en un contexto violento. Como se señala en este artículo, esta región experimentó la presencia de distintos actores armados ilegales por varias décadas, aunque el escalamiento del conflicto armado se produce a finales de los noventa. En este contexto, múltiples formas de violencia tomaron lugar, incluyendo desplazamiento forzado, masacres, asesinatos, intimidaciones a alcaldes, concejales y líderes sociales, así como de la siembra de minas antipersona.

En cuanto a las teorías sobre democratización y consolidación democrática que han orientado la investigación sobre la democracia en 
América Latina, algunas teorías asocian altos niveles de violencia con el fracaso de la democracia. En el presente trabajo, asumimos la postura de Arias y Goldstein (2010), quienes consideran que la violencia no es indicativa de fallo democrático, sino que puede ser entendida como "crítica en la fundación de las democracias latinoamericanas" (Arias \& Goldstein, 2010, p. 5). Estos autores han propuesto la categoría de pluralismo violento para entender y caracterizar las democracias latinoamericanas en las que múltiples formas de violencia tienen expresión. De acuerdo con estos autores, el pluralismo violento se refiere a "estados, élites sociales y grupos subalternos que emplean violencia en la búsqueda de establecer o refutar regímenes de ciudadanía, justicia, derechos y el orden social democrático" (Arias \& Goldstein, 2010, pp. 4-5). ${ }^{2}$

El propósito de este artículo no es entender de manera general las relaciones entre democracia y violencia, sino que nos limitamos a examinar cómo se relacionan las organizaciones de víctimas y de mujeres con la democracia local en un contexto en el que actores estatales y no estatales hacen uso de la violencia en el marco del conflicto armado, en muchas ocasiones contra los miembros de estas organizaciones o las comunidades a las que pertenecen. Como mostraremos más adelante, estas organizaciones de víctimas y de mujeres recurren más bien a acciones de carácter no violento para plantear sus reivindicaciones ante las instituciones y la sociedad y para resistir la violencia y dar respuesta a los efectos de la guerra en sus vidas. En este sentido, esta investigación brinda elementos para entender cómo estas relaciones con la democracia se tejen y son mediadas por un contexto que es violento, incluso en el escenario postdesmovilización en el que surgieron otras formas de violencia como resultado del rearme de las estructuras paramilitares y en el que algunas de estas mujeres han recibido amenazas por las acciones que promueven.

Esta investigación muestra que las relaciones que estas organizaciones han establecido con los discursos institucionales de ciudadanía y

\footnotetext{
2 Para un análisis de la democracia colombiana y el pluralismo violento véase Roldán (2010) y Ramírez (2010).
} 
participación y la esfera política formal se dan desde mucho antes del escalamiento del conflicto armado, aunque adquieren mayor visibilidad en este contexto y en el escenario posterior a la Ley de Justicia y Paz.

La segunda dimensión de análisis para entender las relaciones de estas organizaciones con la democracia local es moldeada de manera más clara por el contexto del conflicto armado. En este contexto, los discursos de ciudadanía y participación también son apropiados y redefinidos por esas organizaciones para dar respuesta a los efectos del conflicto armado. En relación con ello, la democracia participativa y desde abajo adquiere un lugar central. Sin embargo, la democracia participativa adquiere un significado para las organizaciones de víctimas y mujeres que está íntimamente ligado a su cotidianidad y, en particular, a los efectos de la guerra en sus vidas y sus comunidades, así como a los procesos de reconstrucción impulsados por estas organizaciones. Esta mirada y, principalmente, el énfasis que este artículo pone en la relevancia de tomar como punto de partida los significados que las organizaciones de víctimas y de mujeres le atribuyen a la democracia, es importante porque permite visibilizar formas de relacionamiento y prácticas que los actores locales consideran como democráticas y que en otros contextos podría no ser consideradas como tales.

En términos metodológicos, es relevante mencionar que la investigación se desarrolló en el periodo comprendido entre agosto de 2011 y julio de 2012, e incluyó cuatro visitas de campo a algunos municipios del Oriente Antioqueño, aunque se concentró particularmente en el municipio de San Carlos. Los municipios visitados fueron Rionegro, La Unión, Granada, Marinilla y San Carlos. Una visita de campo adicional fue realizada durante julio de 2013. Se realizaron 27 entrevistas a miembros de Aproviaci, Amor, algunas mujeres de Provísame, Conciudadanía, el Programa de las Naciones Unidas (PNUD), miembros del Centro de Acercamiento para la Reparación y Reconciliación (CARE), funcionarios públicos de San Carlos y Medellín, y algunos habitantes no vinculados a estos procesos organizativos. 


\section{Dinámicas del conflicto armado en el Oriente Antioqueño}

El desarrollo del Oriente Antioqueño ha estado asociado a la expansión de la industria del Valle de Aburrá y a proyectos nacionales de generación de energía eléctrica y de comunicación tanto vial como aérea. Entre 1978 y 1984 se construyó el complejo hidroeléctrico más importante del país en la subregión de embalses, lo cual significó el desplazamiento de cientos de familias; algunas de ellas negociaron con el Estado en condiciones precarias y otras fueron sacadas a la fuerza de sus territorios. Aun cuando este proceso revistió violencia, la confrontación armada empezó después.

Aunque algunos asentamientos guerrilleros aparecen en la región a finales de los años setenta, no se constituyeron en factores de confrontación a gran escala durante esos años (García, 2011). El conflicto armado en el Oriente Antioqueño aparece de manera tardía, en contraste con lo sucedido en otras subregiones del departamento y del país.

La aparición del ELN en la región se remonta a los años ochenta, cuando se crea en 1985 el Frente Carlos Alirio Buitrago, que operó en principio en la zona de bosques. Posteriormente, el ELN extendió su presencia a la zona de embalses en los noventa, en particular a algunas veredas del municipio de San Carlos y Granada, y luego en San Luis. La persecución al Movimiento Cívico y el asesinato de varios de sus líderes, que tuvo lugar a finales de los ochenta, se constituyó en un escenario propicio para el accionar del ELN en la región, cuya presencia se prologaría hasta finales de los noventa.

Por su parte, las FARC empezaron a hacer presencia en la región desde los ochenta, con el cuarto frente. Posteriormente, tendrían presencia los frentes 9 y 47. El primero operó en los municipios de San Rafael y San Carlos, para luego expandirse a San Luis, Cocorná, Concepción y Alejandría. El frente 47 centró sus operaciones en la zona de Páramos y Bosques, específicamente en Argelia, Nariño, Sonsón y San Francisco (Observatorio del Programa Presidencia de 
Derechos Humanos y DIH, 2004). Hacia finales de los años noventa, las FARC entraron a disputarle la hegemonía en el territorio al ELN, llegando incluso a enfrentamientos armados entre los dos grupos guerrilleros. El ingreso de las FARC se produjo a través de atentados, bombardeos y reclutamiento forzoso, lo que hizo que su presencia fuera asimilada por algunos pobladores como la de un ejército de ocupación. En la segunda mitad de la década de los noventa, este grupo guerrillero amplió sus operaciones a algunos municipios del altiplano (Restrepo, 2010).

A finales de los ochenta las autodefensas que hacían presencia en el Magdalena Medio, bajo el mando de Ramón Isaza, incursionaron en el oriente lejano, particularmente en algunas veredas del municipio de San Carlos; sin embargo, su presencia por esa época fue temporal. En 1997 se produce la entrada de los grupos paramilitares en la región del oriente. Las primeras acciones se dieron en el municipio de Carmen de Viboral, pero rápidamente se extendieron a otros municipios del oriente cercano, la zona de embalses y la zona de páramos (Observatorio del Programa Presidencial de Derechos Humanos $\& \mathrm{DIH}, 2004)$. Los grupos que hicieron presencia en la región fueron las autodefensas del Magdalena Medio, el bloque Metro de las Autodefensas Campesinas de Córdoba y Urabá, el bloque Cacique Nutibara y el bloque Héroes de Granada.

Aunque desde principios de la década de los noventa los territorios se convirtieron en escenarios de confrontación armada entre guerrilla, Estado, narcotraficantes y grupos paramilitares, a raíz del auge del narcotráfico agenciado por el cartel de Medellín y la intensificación del conflicto en el Magdalena Medio, (Novoa, 2009), solo hasta el periodo comprendido entre 1997 y 2007, el escalamiento de la violencia en el Oriente llegó al nivel de crisis humanitaria. Esto se da como consecuencia de la expansión de los grupos guerrilleros ELN y FARC, la ofensiva estatal y la llegada de los grupos paramilitares que buscaban contener el avance de las guerrillas.

De acuerdo con García (2011), este decenio de escalamiento del conflicto armado puede ser dividido en tres períodos. El primero se 
ubica entre 1997 y 2000, en el que el ELN intensifica sus acciones en el eje vial Medellín-Bogotá, las FARC empiezan a hacer presencia en los territorios, y aparecen grupos paramilitares como parte de la estrategia contrainsurgente. El segundo periodo, comprendido entre los años 2000 y 2004, es el más álgido de los tres por la cantidad de acciones perpetradas. En estos años el ELN disminuyó significativamente su accionar, hubo una expansión de la presencia de las FARC y se produjo una especie de relevo entre los grupos paramilitares y las fuerzas armadas, ya que mientras los primeros disminuyeron sus acciones, el ejército aumentó su presencia en la región como resultado de la política de seguridad democrática que empieza con el gobierno de Álvaro Uribe Vélez en el año 2002. Finalmente, entre el año 2005 y 2006 se registró una sensible disminución de las acciones de los grupos armados, como resultado de la desmovilización de los grupos paramilitares vinculados a Carlos Castaño y a Ramón Isaza, por la casi completa desaparición de las acciones por parte del ELN y la arremetida de las fuerzas militares contra las FARC.

\section{Procesos organizativos en el Oriente Antioqueño: de la organización de mujeres al movimiento de víctimas}

El Oriente Antioqueño ha sido una región con gran tradición organizativa; en las décadas de los setenta y ochenta tuvieron expresión los movimientos cívicos en varios de sus municipios. Aunque en principio estas expresiones fueron de carácter local, en los ochenta se logró articular un movimiento regional conocido como el Movimiento Cívico del Oriente Antioqueño (Novoa, 2009), que permitió materializar varias de las demandas y reivindicaciones planteadas por los pobladores de la región ante el Estado. Sin embargo, el Movimiento Cívico del Oriente Antioqueño fue desarticulado a finales de la década, principalmente como consecuencia del auge del paramilitarismo, la represión y el asesinato de líderes cívicos y de izquierda.

En la segunda mitad de la década de los noventa y en los primeros años del nuevo siglo, las acciones colectivas en el Oriente Antioqueño aparecen como una respuesta de la población frente a la intensifica- 
ción del conflicto armado que experimentó la región desde 1997; en el escenario de esta confrontación armada se inició un ciclo de protestas y de resistencia de la población del Oriente Antioqueño frente a los efectos del conflicto armado. En la región empezaron a tener lugar movilizaciones locales, como marchas, jornadas del silencio, concentraciones e intentos de acercamientos con los actores armados.

Cabe mencionar que la diócesis Sonsón-Rionegro jugó un papel importante en este proceso, mediante la convocatoria que hizo desde 1994 a diversos líderes y sectores sociales, para buscar soluciones a la crisis humanitaria que experimentaba la región, así como la realización de distintos foros por la paz. Además, realizó un trabajo de mediación y acompañamiento a las comunidades del Oriente Antioqueño, en el marco de las labores emprendidas por la Comisión Vida, Justicia y Paz entre 1994 y 1998. Entre sus acciones pueden mencionarse "el diálogo con los grupos armados, los desbloqueos a poblaciones amenazadas y el acompañamiento pastoral a las comunidades afectadas por el conflicto" (Corporación Vida, Justicia y Paz, 2011, p. 21).

En el marco de este trabajo que se venía desarrollando en la región con las comunidades, se presentó una propuesta al Gobierno nacional con el objetivo de crear una comisión subregional para gestiones humanitarias en la región del Oriente Antioqueño, cuyo propósito fundamental era lograr "acuerdos mínimos humanitarios" en medio del conflicto armado (Corporación, Vida, Justicia y Paz, 2011, p. 22). Aunque esta propuesta fue rechazada por el Gobierno del presidente Pastrana, en la región tuvieron lugar acercamientos humanitarios con los grupos armados que fueron liderados por los alcaldes del Oriente Antioqueño ${ }^{3}$ y que contaron con el acompañamiento de las asambleas comunitarias, la Corporación Vida, Justicia y Paz y el aval del gobernador.

Durante este periodo también tienen lugar otros procesos organizativos como el de la Asociación de Mujeres del Oriente (AMOR)

3 Véase “Rebeldes con causa”, en: Revista Semana, Edición 1004, Agosto 27 de 2001. 
y, posteriormente, la Asamblea Provincial del Oriente Antioqueño. AMOR es una organización que surge en 1994 y que está integrada por organizaciones y/o redes de mujeres de los 23 municipios del Oriente Antioqueño. Por su parte, la Asamblea Provincial del Oriente Antioqueño tuvo como función analizar la situación de conflicto y crisis humanitaria de los 23 municipios de la región.

En los años siguientes se dieron dos grandes cambios que afectaron los procesos organizativos y la acción colectiva en la región. Por un lado, se empieza a implementar la política de Seguridad Democrática promovida por el presidente Álvaro Uribe, y por el otro tiene lugar el proceso de desmovilización de los grupos paramilitares, y a partir de ello, la Ley de Justicia y Paz. Con la política de seguridad democrática y el proceso de desmovilización se logró disminuir los índices de violencia de la región, lo cuales fueron el factor que motivó la acción colectiva de los pobladores en años anteriores. La desmovilización, a su vez, trajo consigo la ley de Justicia y Paz, que propició el posicionamiento social y político de un nuevo actor que había empezado a organizarse en la región: las víctimas del conflicto armado. En este actor nos centramos a continuación, a partir de la experiencia del movimiento regional de víctimas y del proceso de víctimas seguido por el municipio de San Carlos en el Oriente Antioqueño.

\subsection{La experiencia de Aproviaci}

Para entender el surgimiento de Aproviaci (Asociación Provincial de Víctimas a Ciudadanas) es necesario considerar no solo el protagonismo que adquiere el tema de víctimas con la implementación de la ley de Justicia y Paz, sino el proceso de organización de mujeres que se va dando paulatinamente en el Oriente Antioqueño y que va a concretarse en AMOR. Este proceso organizativo, que se remonta a la década de los ochenta, empezó a perfilarse de manera incipiente a partir del trabajo que se desarrolló entre las comunidades y la Asociación de Centros de Atención al Preescolar en Antioquia (Acaipa) desde la segunda década de los setenta. Aunque el trabajo de Acaipa estuvo centrado en principio en la organización de la comunidad para la atención a niños y niñas menores de 7 años, se fue generando un escenario para trabajar también con 
las mujeres y contribuir a su organización en la región. En este contexto empezaron a tener lugar encuentros de mujeres y se fue generando un movimiento incipiente, que constituye el precedente de AMOR (Mujer, cofundadora de Acaipa y de conciudadanía,comunicación personal, noviembre de 2011).

Por su parte, el proceso de Acaipa constituyó el antecedente de Conciudadanía, que es una organización no gubernamental local creada en 1991 y que jugó un papel muy importante durante las siguientes décadas al impulsar y apoyar distintas organizaciones sociales de la región. Conciudadanía apareció como una respuesta al impulso que la Constitución de 1991 le dio a la democracia participativa. Esta organización "recogió muchos de los elementos con los que se venía trabajando en Acaipa", pero pretendió "hacer el tránsito de la participación comunitaria a la participación ciudadana, bajo el lema 'para que los derechos sean hechos"' (Mujer exmiembro de Conciudadanía, comunicación personal, noviembre de 2011).

Con la aparición de la consejería para la mujer de Antioquia en 1992, se impulsó en la región "la creación y legalización de asociaciones de mujeres en los municipios” (Londoño, Marín \& Alzate, 2005, p. 34). Por otro lado, en concertación con esta consejería, Conciudadanía desarrolló un proyecto que se denominó "Mujer al poder local”, cuyo propósito era la formación de las mujeres en ciudadanía y política. En este contexto surgió AMOR en 1994, como una organización de segundo grado que recogía las organizaciones de mujeres a nivel municipal en el Oriente Antioqueño.

Durante los años siguientes, Conciudadanía impulsó una serie de procesos de formación en los que participaron las mujeres de AMOR. En el año de 1996 se inició un proyecto de organización y participación política de las mujeres denominado "Mujer por la equidad de género, de la casa a la plaza", que buscaba "cualificar el liderazgo social y político de las mujeres y fortalecer las organizaciones a las cuales pertenecían” (Londoño, Marín \& Alzate, 2005, p. 36). Entre 1999 y 2001 se desarrolla la Escuela de Gestión Pública con Perspectiva de 
Género, que posibilitó la formación de las mujeres de AMOR en aras de promover su participación en espacios públicos.

A finales de los años noventa, al mismo tiempo que se daban estos procesos de formación, se produjo un escalamiento del conflicto armado, lo que conduce a poner en un primer plano la discusión sobre sus efectos en la vida familiar, en las comunidades y, particularmente, en las mujeres. En el marco de los encuentros entre mujeres que se hacían en la escuela de gestión pública con perspectiva de género, fue necesario generar un espacio para desarrollar tertulias nocturnas que "permitieron la reflexión sobre los efectos de la guerra en la población civil y especialmente en las mujeres y las acciones o propuestas que desde ellas se podían promover o realizar en la región" (Londoño, Marín \& Alzate, 2005, p. 31). Esto condujo a Conciudadanía a formular una experiencia piloto de atención emocional de las mujeres para formar lideresas comunitarias que "pudieran servir de apoyo a otras mujeres" de sus localidades, en la "elaboración de sus duelos y la construcción de alternativas en medio de la guerra" (Cinep, Conciudadanía \& Amor, 2007). En 2003, se desarrolló la primera experiencia piloto, bajo el proyecto formación de mujeres líderes sociales en territorio de conflicto armado, Promotoras de Vida y Salud Mental (Provísame), en el que participaron las mujeres de AMOR.

Este modelo es enriquecido en el marco de la alianza que se dio entre Conciudadanía, el Programa de Paz del Cinep ${ }^{4}$ y AMOR para trabajar de manera conjunta en la región. En el 2004, se reformuló la propuesta desde los aportes de las tres instituciones y se implementó a través del proyecto Promotoras de Vida y Salud Mental (Provísame), por la reconciliación y la reconstrucción del tejido social en el Oriente Antioqueño. ${ }^{5}$ Dicho proyecto no solo buscaba dar continuidad a la capacitación de mujeres

\footnotetext{
4 El Programa de Paz del Cinep, que empieza a hacer presencia en la región a partir de entonces, inició un trabajo con algunas mujeres de Amor que consistió en talleres de habilidades para la paz, el programa de formación de promotoras de vida y salud mental, y la formación en estrategias de acción no violenta (Cinep, Conciudadanía \& Amor, 2007).

5 Las Provísames -en su mayoría víctimas- son mujeres que han sido capacitadas para brindar apoyo psicosocial a las abrazadas en su proceso de recuperación interior y sanación frente a los dolores y sufrimientos vividos en el marco del conflicto armado. Las abrazadas
} 
lideresas para que pudieran brindar apoyo psicosocial a otras mujeres en sus localidades, sino también aportar a la organización de las víctimas (Cinep, Conciudadanía \& Amor, 2007).

Es en el marco de estos procesos que surgen las organizaciones de víctimas en los municipios y posteriormente la organización regional de víctimas Aproviaci. Una de las mujeres entrevistadas, sostiene que el "proceso de las Provísames permitió que empezaran a darse las primeras organizaciones de víctimas a nivel local” (Mujer miembro de la junta directiva de Aproviaci, comunicación personal, mayo de 2012). En este proceso también tuvo relevancia el acompañamiento realizado por los Comités de Reconciliación que empezaron a hacer presencia en cada uno de los municipios. A través de estos comités, que fueron apoyados por Conciudadanía y el Programa de la Paz del Cinep, se empieza no solo a hablar de lo psicosocial, sino de lo jurídico y de la incidencia política (Mujer miembro de la junta directiva de Aproviaci, comunicación personal, agosto de 2011).

En el contexto de este proceso de constitución de organizaciones de víctimas locales, aparece Aproviaci como una asociación de víctimas de carácter regional. En la semana por la paz celebrada en 2005 tuvo lugar un encuentro en el que participaron fundamentalmente mujeres del Oriente Antioqueño, ${ }^{6}$ y en el que se presentó una propuesta para "constituir una asociación de carácter regional que representara los intereses de las víctimas" (Mujer miembro de Aproviaci, comunicación personal, mayo de 2012). Durante el 2006 se convocaron diferentes asambleas, reuniones y encuentros en cada uno de los municipios, que contaron con la participación de los comités de reconciliación y con el apoyo de Conciudadanía y el Cinep, con el propósito de darle forma a esa propuesta. Es así como a finales de ese año se constituye legalmente Aproviaci.

son las víctimas que participan de los abrazos, que constituye un espacio colectivo donde es posible expresarse sin miedo. Véase Cinep, Conciudadanía \& Amor (2007).

6 "Este encuentro contó con la participación de aproximadamente 500 personas provenientes de todos los municipios del Oriente Antioqueño". (Mujer miembro de la junta directiva de Aproviaci, comunicación personal, agosto de 2011). 
Desde 2006, Aproviaci empieza a operar como asociación regional que busca "hacer acompañamiento a las organizaciones de víctimas en lo local, para desde ahí direccionar un trabajo regional" (Mujer miembro de la junta directiva de Aproviaci, comunicación personal, mayo de 2012, Rionegro). Esta organización empezó a trabajar con las víctimas de la región y a presentar propuestas para hacer incidencia política en lo local y lo nacional. Desde su creación, Aproviaci ha jugado un papel fundamental en el acompañamiento y fortalecimiento de las organizaciones de víctimas en la región del Oriente Antioqueño.

Empezamos a trabajar agenda con las víctimas: propuestas para hacer incidencia política en lo local, a nivel nacional, incluso iban propuestas para los mismos actores armados, que han hecho tanto daño, y se empezó a trabajar en cuatro líneas: apoyo psicosocial, asesoría jurídica para las víctimas, fortalecimiento organizativo en el ámbito local y comunicación (Mujer miembro de la junta directiva de Aproviaci, comunicación personal, agosto de 2011).

Por otro lado, cabe mencionar que las acciones de Aproviaci son de resistencia no violenta, por lo que las movilizaciones y actos simbólicos que se han realizado, como las acciones colectivas que han tenido lugar en varios municipios con el propósito de recordar las víctimas y expresar públicamente el dolor, las trochas por la vida y la reconciliación, los plantones y las jornadas de la luz, ${ }^{7}$ han jugado un papel central de visibilización de las víctimas y por otro lado, de resistencia frente a la violencia. ${ }^{8}$

\footnotetext{
7 Investigaciones previas destacan cómo en muchas de estas acciones de resistencia se percibe la influencia de la religión católica, ya que se movilizan símbolos y ritos propios de ella. Según el Grupo de Memoria Histórica GMH (2009, p. 85), “Las jornadas de la luz fueron originadas en una experiencia de celebración del día de las madres y la Virgen María, y el encendido de las velas se hizo extensivo a los actos de la memoria. Así, cada primer viernes del mes, en cada plaza principal de los municipios del Oriente Antioqueño se congregan las víctimas para encender una luz en memoria de las víctimas y como estrategia para vencer el miedo impuesto por la violencia". Para ampliar este aspecto véase Peralta (2009).

8 Véase. Villa, Sánchez \& Téllez (2007, p. 38).
} 
Como se ha mostrado, la experiencia organizativa en torno a Aproviaci no puede entenderse de manera desligada de lo que ha sido la organización de mujeres en la región, ni de los procesos de formación política y ciudadana que han tenido lugar en el Oriente Antioqueño desde los noventa (Mujer exmiembro de Conciudadanía, comunicación personal, noviembre de 2011).

Por otro lado, los procesos de formación política y ciudadana, y el programa de las Provísames impulsado por Conciudadanía y el Programa por la Paz del Cinep han tenido una gran incidencia en los procesos organizativos que han tenido lugar en el Oriente Antioqueño. Como veremos más adelante, tanto en el caso de AMOR como en el de Aproviaci, el tema de la ciudadanía y los derechos cobra relevancia en el discurso y las prácticas de estas organizaciones. Así mismo, las promotoras de vida y salud mental han jugado un papel importante en los procesos organizativos de víctimas del nivel local y regional. Las Provísames ${ }^{9}$ no solo han sido las encargadas de asumir el trabajo psicosocial con las víctimas, sino que algunas de ellas se encuentran hoy vinculadas de manera directa a las organizaciones de víctimas.

\subsection{La experiencia del CARE en el municipio de San Carlos}

En los últimos años, el proceso organizativo en el municipio de San Carlos ha girado en torno al proceso emprendido por las víctimas del conflicto armado y, específicamente, por el Centro de Acercamiento para la Reparación y Reconciliación (CARE). Este centro es una iniciativa de miembros de la comunidad, impulsada en principio por un grupo de mujeres víctimas del conflicto, lideradas por una concejala que, al igual que otros habitantes de San Carlos, experimentó la pérdida de sus seres queridos.

Antes de la creación del CARE, las víctimas en este municipio venían trabajando fundamentalmente en la documentación de los casos de

\footnotetext{
9 De acuerdo con la mujer entrevistada miembro de junta directiva de Aproviaci, la región cuenta aproximadamente con unas 120 personas que fueron capacitadas como Provísames, principalmente mujeres, aunque también algunos hombres.
} 
sus familiares desaparecidos. El CARE también fue precedido por un taller al que asistieron víctimas y desmovilizados de los grupos armados que provenían del mismo municipio y de otras regiones. El taller fue una iniciativa de las víctimas como respuesta a la presencia de varios desmovilizados en el municipio. De acuerdo con el testimonio de una de las mujeres entrevistadas en San Carlos, se ubicaron 45 desmovilizados que empezaron a cruzarse en distintos espacios con las víctimas, a establecer vínculos con algunos miembros de la población sancarlitana y a conformar familias. Esta situación motivó la realización de un cabildo abierto en agosto de 2006, que buscaba involucrar más población para pensar qué se podía hacer en aras de lograr una sana convivencia en el municipio. Después del cabildo, se generó una política pública municipal por medio de la cual se creó el CARE.

Con la creación del CARE se generó un espacio para que habitantes del municipio de San Carlos, y en particular las víctimas de los actores armados, reconstruyan la memoria de las violencias que tuvieron lugar en este municipio, a partir de sus experiencias personales, sin importar si son víctimas de la guerrilla, de los paramilitares o de la fuerza pública. Este espacio también ha permitido enfrentar el dolor e iniciar los procesos de duelo y sanación (GMH, 2011). Además, el CARE se constituye como un escenario desde el que las víctimas del conflicto, principalmente mujeres, se han empoderado para plantear sus reivindicaciones ante las instituciones del Estado, la comunidad, la sociedad e incluso, ante los mismos desmovilizados o excombatientes que habitan en el municipio.

Desde el CARE se ha liderado el proceso de construcción de memoria y se han promovido diversas actividades e iniciativas, como el trabajo psicosocial que se ha hecho con las víctimas y los desmovilizados, la búsqueda de los cadáveres de los desaparecidos, la resignificación de algunos lugares del municipio donde ocurrieron atrocidades, el proyecto de las cartografías para la localización de las fosas comunes, el trabajo de memoria histórica con algunas de las familias que han retornado al municipio y la construcción de un monumento a 
la memoria, inaugurado en 2011, que fue denominado "El Jardín de la Memoria".

El trabajo que se ha hecho en San Carlos con víctimas y desmovilizados se ha diferenciado de otros procesos en el Oriente Antioqueño, debido a que este municipio le ha apostado a la reconciliación entre víctimas y victimarios. En el marco de este trabajo con víctimas y desmovilizados, el CARE gestionó y desarrolló un proyecto de apoyo psicosocial a víctimas y victimarios para la reconstrucción del tejido social. $^{10}$

Entre los otros proyectos que han sido impulsados por el CARE cabe destacar la resignificación de lugares en el municipio donde ocurrieron atrocidades; por ejemplo, ha promovido diversos actos simbólicos para resignificar la casa donde funcionó el comando paramilitar en el casco urbano —antiguo hotel Punchiná, conocida como 'la casita del terror'-, donde se cometieron torturas, asesinatos y desapariciones. En esta casa, que es el lugar donde actualmente funciona el CARE, se han realizado oraciones, talleres, jornadas de la luz en las noches y otros actos simbólicos encaminados a cambiar el significado del lugar. ${ }^{11}$

10 En este documento no se aborda lo relativo a las dificultades que han enfrentado este tipo de apuestas por la reconciliación en el caso de San Carlos, así como cuáles son sus límites o fortalezas para la construcción del tejido social. Algunos elementos de análisis en esta dirección puede verse en Osorio (2013) y GMH (2011).

11 Según testimonios de miembros del CARE, la decisión de ocupar esta casa obedeció en principio a razones circunstanciales, debido a que estaba en proceso de extinción de dominio y el CARE no tenía un lugar donde funcionar. Sin embargo, el CARE consideró que desarrollar sus actividades en esta casa era una oportunidad para promover el acercamiento entre las víctimas y victimarios, para lo cual se realizaron ejercicios de memoria en aras de posibilitar el reconocimiento de lo sucedido como primer paso para la reconciliación. En este sentido la casita del terror fue convertida en un espacio de memoria, desde la que es resignificada en la medida en que no es asociada al dolor y muerte sino un escenario de esperanza y de vida (Nieto, 2014). 


\section{Discursos y prácticas de ciudadanía y participación: relación con la esfera institucional y la cotidianidad}

En las últimas dos décadas, en el Oriente Antioqueño se evidencia una estrecha relación entre los procesos organizativos de mujeres y víctimas, y la esfera institucional. Los discursos de participación y ciudadanía apropiados y redefinidos por estas organizaciones, así como sus prácticas en torno a estos temas, han jugado un papel importante en construir esta relación. En este contexto, los procesos organizativos tanto de víctimas como el de mujeres han buscado encontrar apoyos e interactuar con las instituciones en la esfera política formal, en aras de ser escuchadas y posicionar sus reivindicaciones en el espacio de lo público. Sin embargo, esta relación también pasa por expresar las tensiones entre los procesos organizativos y las instituciones estatales, más específicamente frente a temas cruciales como la definición de víctima o el tema de la reconciliación.

De otra parte, la relación de estos procesos organizativos con la democracia involucra también una apropiación y redefinición de los discursos de ciudadanía y participación por parte de organizaciones de víctimas y de mujeres, con el propósito de incidir y transformar su cotidianidad en un contexto que ha sido fuertemente afectado por la violencia política. El papel que han jugado las Provísames en el territorio, las movilizaciones y resistencias en contra de los efectos del conflicto armado o las acciones emprendidas por mujeres y víctimas para reconstruir el tejido social, ilustran este último aspecto. En el contexto del conflicto armado y sus efectos, la democracia y más específicamente la democracia participativa adquiere un significado para las organizaciones de víctimas y de mujeres, que está íntimamente ligado a su cotidianidad y, en particular, a los efectos de la guerra en sus vidas y sus comunidades, así como los procesos de reconstrucción impulsados por estas organizaciones.

A continuación examinamos la relación de estos procesos organizativos con la esfera institucional, para lo cual nos centramos en los discursos de ciudadanía, participación y reconciliación impulsados en el marco de la Constitución Política de 1991 y la Ley de Justicia y 
Paz. De igual manera, examinamos cómo la apropiación y redefinición de estos discursos por parte de víctimas y mujeres no solo ha sido usada para establecer puentes con la esfera institucional, sino que está estrechamente relacionada con el ámbito más cotidiano de sus vidas y comunidades desde el que se busca no solo incidir, sino desde el que se construye la ciudadanía y la participación.

\subsection{Discursos sobre la ciudadanía y participación}

El proceso incipiente de organización de mujeres que venía gestándose desde finales de los ochenta en el Oriente Antioqueño, encuentra un escenario muy propicio en la Constitución de 1991 y su discurso participativo. De hecho, Conciudadanía nace estrechamente ligada al discurso de participación ciudadana impulsado por la Constitución de 1991, y con ello, al discurso sobre los derechos. Una de las mujeres entrevistadas, ex miembro de Conciudadanía sostiene al respecto:

Cuando nos dimos cuenta de la Constitución de 1991, empezamos a ver que la Constitución tenía toda la filosofía que nosotros habíamos trabajado sobre la democracia, el poder del pueblo, cantidades de cosas que antes eran subversivas. Entonces, cuando vimos que esta constitución nos contenía dijimos "ahora tenemos el instrumento legal para trabajar sobre esto", y se nos abrieron los horizontes y dijimos "organicemos una institución que permita que eso que estamos hablando se convierta en realidad" y ahí dimos el paso de Acaipa a Conciudadanía, y lo que buscábamos era hacer un cambio de la participación comunitaria a la participación ciudadana con el lema "para que los derechos sean hechos" (Mujer exmiembro de Conciudadanía, comunicación personal, noviembre de 2011).

A su vez, Conciudadanía y su discurso sobre la participación ciudadana y los derechos va a jugar un papel muy importante en los procesos de formación política y ciudadana y de organización de las mujeres en la región. En las conversaciones y entrevistas que se realizaron en el marco del trabajo de campo desarrollado en esta investigación, tanto con mujeres de AMOR, como de Aproviaci y del CARE, temas como 
el de participación, derechos y ciudadanía ocupan un lugar central en el discurso que enuncian sobre sus organizaciones.

En este sentido, es posible sostener que los procesos organizativos de AMOR, Aproviaci y el CARE han tenido un fuerte vínculo con lo institucional desde su momento de gestación. En el caso de AMOR, la organización empieza a tomar forma no solo con el apoyo e impulso proveniente de Conciudadanía, sino como consecuencia del giro en las políticas de mujer que empiezan a ser promovidas a nivel departamental en Antioquia, con la creación de la Oficina de la Mujer. Por otro lado, los procesos de formación política y luego el de las Promotoras de Vida y Salud Mental en el que participaron las mujeres de AMOR, se inscribieron desde el principio en el marco institucional creado a partir de la Constitución de 1991, en particular, a partir de la apropiación de los discursos de participación y ciudadanía promovidos por esta. De forma más reciente, esta relación con lo institucional se ha establecido también mediante estrategias y acciones de estos procesos organizativos para incidir más directamente en los espacios de decisión pública como mostramos al final de este acápite.

Por otro lado, la apropiación y redefinición de los discursos de ciudadanía y participación por parte de organizaciones de víctimas y de mujeres no solo ha incidido y ayudado a transformar su cotidianidad, sino que ha permitido que la democracia adquiera un nuevo significado para estas mujeres. En el marco del escalamiento del conflicto armado y en el periodo posterior, la apropiación, redefinición y puesta en práctica de los discursos de ciudadanía y participación por parte de organizaciones de mujeres y de víctimas les han permitido encontrarse y construir relaciones con otras mujeres en la misma situación, hablar sobre sus experiencias en medio de la guerra, trabajar el dolor y el duelo, dar un nuevo sentido a sus vidas, articularse y organizarse para alzar sus voces para plantear sus reivindicaciones ante el Estado y ante sus comunidades e incluso, redefinir sus relaciones en el ámbito de lo doméstico. De esta manera, la cotidianidad de estas mujeres, marcada por los efectos de la violencia en sus vidas, por su invisibilización en los procesos participativos y su papel relegado fundamentalmente a lo doméstico, se ha ido transformando a partir del encuentro con el 
otro, los procesos organizativos y la apropiación y puesta en práctica de los discursos de ciudadanía y participación.

En las entrevistas realizadas a las mujeres de AMOR y Aproviaci se alude a distintos aspectos que ilustran cómo su vinculación a los procesos participativos y organizativos incide en su vida cotidiana. Así, algunas se refirieron a la manera como los espacios generados en el marco de los procesos organizativos, de ciudadanía y de participación les permitieron hacer frente a los efectos del conflicto armado y no quedarse en el aislamiento o la victimización. Más específicamente, algunas de estas mujeres hicieron referencia a la importancia de los auxilios emocionales y, específicamente, al programa de las Promotoras de vida y Salud Mental, que no solo les permitió elaborar el duelo y superar el dolor, sino también " formarse [como] líderes en los municipios, líderes mujeres que van adquiriendo herramientas para hacer apoyo psicosocial a otras víctimas" (Mujer miembro de AMOR, comunicación personal, mayo de 2012). Las movilizaciones, jornadas de la luz y otras acciones de resistencia no violenta también han fortalecido la articulación y organización de estas mujeres y han sido importantes para la reconstrucción del tejido social, pero, además, han tenido efectos en su vida cotidiana en la medida en que han cambiado la manera como se relacionan entre ellas y sus comunidades. Finalmente, algunas mujeres mencionaron que su vinculación a los procesos organizativos y participativos ha tenido incidencia en sus relaciones en el ámbito de lo doméstico. Así mismo, la participación en estos espacios les ha permitido cuestionarse e incluso redefinir sus relaciones en el ámbito doméstico, dominadas en muchos casos por el machismo y por los roles tradicionales que se espera que las mujeres asuman.

Un aspecto importante de esta mirada sobre el tema de la cotidianidad no es solo que los procesos organizativos y la apropiación y puesta en práctica de los discursos de ciudadanía y participación han incidido en la vida cotidiana de estas mujeres, sino que desde allí la ciudadanía, la participación y la democracia adquieren otro significado. Un ejemplo en esta dirección es el proceso de los pasos y abrazos que se ha dado en el marco del acompañamiento psicosocial de las Pro- 
vísames. Una de las mujeres entrevistadas señala que en este espacio de los abrazos "se volvió a retomar la importancia de estar en espacios de participación, la importancia de los espacios de los abrazos, que ya son espacios de participación" (Mujer miembro de AMOR, comunicación personal, agosto de 2011). En este sentido, el proceso de los abrazos no solo constituyen un espacio para superar el dolor y atender lo psicosocial, sino que son percibidos por estas mujeres como espacios de participación y de ejercicio de la ciudadanía. Estos espacios no solo buscan que las mujeres puedan tramitar el dolor, sino que se organicen, superen el lugar de la victimización y se conviertan en ciudadanas capaces de reclamar sus derechos. Sin embargo, estas apuestas políticas y sociales de las organizaciones de mujeres y de víctimas están estrechamente relacionadas con sus experiencias de vida y su cotidianidad. En este contexto, la democracia, y de manera más específica, la participación y la ciudadanía no se entienden solo como un mecanismo para incidir en la esfera política formal, para relacionarse con las instituciones o reclamar derechos, sino que está ligada con la transformación del dolor y las relaciones con el vecino, la reconstrucción de lazos de confianza y la capacidad para organizarse.

\subsection{Posicionamiento de las víctimas y miradas sobre la Reconciliación}

La Ley de Justicia y Paz generó las condiciones que permitieron el posicionamiento político y social de un nuevo actor en el Oriente Antioqueño: las víctimas del conflicto armado. Si bien es cierto que las organizaciones de víctimas en esta región empiezan a conformarse desde antes de la entrada en vigencia de la ley, específicamente en el marco de los procesos de formación de las Promotoras de Vida y Salud Mental, la clasificación jurídica que la ley hizo de las víctimas y los victimarios generó "una apertura del espacio social y político en el que se constituyen nuevos sujetos políticos que emprenden una lucha por su posicionamiento dentro del mismo" (Delgado, 2011, p. 14).

En el Oriente Antioqueño, esta lucha ha estado presente en el proceso emprendido por el movimiento de víctimas en la región. Desde Aproviaci se ha buscado resignificar el concepto de víctima. La mirada 
que esta organización asume sobre las víctimas no pone énfasis en su vulnerabilidad, impotencia o incapacidad de acción; por el contrario, busca empoderar la persona y posibilitar que sea reconocida como ciudadana y como sujeto de derechos, con capacidad de acción. Con esto se recupera todo el legado del concepto de ciudadanía en el marco de los procesos de capacitación política y ciudadana, así como de formación de las Provísames y se pone énfasis en la democracia desde abajo. Aquí se habla de víctimas en un sentido muy específico, se alude a víctimas que no se quedan en el dolor, el miedo y la pasividad, sino que tienen capacidad de organizarse y de actuar, de empoderarse y plantear sus reivindicaciones ante la sociedad y el Estado.

El tema de la reconciliación también nos permite analizar las relaciones entre los procesos organizativos y los discursos y prácticas de la democracia en las dos direcciones propuestas en este documento. Por un lado, se evidencian las relaciones y tensiones entre las organizaciones de víctimas y la esfera política formal y, más específicamente, las políticas institucionales que empiezan a impulsar la reconciliación y el trabajo entre víctimas y victimarios. Estas tensiones también se manifiestan entre las organizaciones AMOR, Aproviaci y el CARE y otros actores que han hecho presencia en la región, como Conciudadanía y el Programa por la Paz del Cinep, debido a las distintas posiciones asumidas frente al tema de la reconciliación. La articulación de los procesos organizativos de mujeres y víctimas con las instituciones estatales no implica que aquéllas no hayan asumido posturas críticas frente a algunas de las políticas que estas últimas han implementado en el territorio.

De otra parte, la forma como ha sido entendida la reconciliación por las mujeres que participan en los procesos organizativos ha jugado un papel importante en la reconstrucción del tejido social y ha incidido en la cotidianidad de mujeres y víctimas trastocada por la guerra. La reconciliación empieza a ser pensada por las mujeres de AMOR en el año 2001; la preocupación por este tema se da como respuesta a la situación que experimentaba para entonces el Oriente Antioqueño, caracterizada por la vinculación de hombres y mujeres de la misma comunidad a diferentes actores armados, así como frente a la per- 
cepción de estas mujeres sobre las consecuencias que esta situación había generado en términos de ruptura del tejido comunitario y de las relaciones familiares.

En el marco del proyecto Promotoras de Vida y Salud Mental se incorpora el tema de la reconciliación, que es concebida no como el acercamiento entre víctimas y victimarios, sino de manera más amplia como reconstrucción del tejido social. Desde esta mirada, se consideró que el encuentro con otros es fundamental, pues permite "transformar y significar de otra manera lo vivido." Los abrazos juegan un papel central para estas mujeres, puesto que generan "una dinámica colectiva que permite resignificar lo vivido, hablar de ello, recuperar la confianza, encontrarse con otras y salir del anonimato en que habían quedado por la experiencia de victimización" (Villa, Sánchez \& Téllez, 2007, p. 114). Es por esto que la reconciliación "adquiere fuerza en lo colectivo y en los espacios compartidos" (Villa, Sánchez \& Téllez, 2007, p. 114). Por otro lado, aunque estas mujeres reconocen que la reconciliación también significa aprender a convivir con los victimarios, consideran que este tipo de encuentros requieren de unas condiciones que no siempre están dadas, como los son el desmonte real de las estructuras sociales, políticas, económicas y militares de los actores armados, el esclarecimiento de la verdad sobre lo sucedido o las garantías de no repetición (Mujer miembro de Aproviaci, comunicación personal, mayo de 2012).

La implementación del proyecto de las Promotoras de Vida y Salud Mental no estuvo libre de tensiones y rupturas entre AMOR, Conciudadanía y el Programa por la Paz del Cinep, producto de las diferencias entre estas organizaciones con respecto al tema de reconciliación y el trabajo con víctimas y desmovilizados. Estas divergencias se hicieron evidentes e insostenibles en la convocatoria que se hizo en 2005 para el segundo proceso de formación de las Provísames, lo que condujo a la ruptura de la alianza que se había realizado entre el Programa por la Paz del Cinep y Conciudadanía.

Mientras Conciudadanía estuvo de acuerdo en iniciar un trabajo con víctimas y victimarios y reunirlos en un mismo espacio, el Programa 
por la Paz del Cinep y AMOR fueron más bien renuentes a aceptar este tipo de encuentros. De acuerdo con una de las mujeres entrevistadas, la aproximación de Conciudadanía al tema de reconciliación no necesariamente implica el establecimiento de "relaciones interpersonales entre víctimas y desmovilizados", sino más bien la "construcción de confianza cívica y reciprocidad democrática". Sin embargo, esto supone reconocer que es importante generar espacios donde todos los actores del municipio puedan participar, incluyendo a actores que estuvieron en la ilegalidad como los desmovilizados, así como considerar los puntos de vista de cada uno de ellos con el propósito de "incluirlos y hacer posible una convivencia entre todos y todas" (Mujer ex miembro de Conciudadanía, comunicación personal, Noviembre de 2011). Lo que se busca con esto es la construcción de la democracia local, para lo cual resulta indispensable lograr la confianza entre ciudadanos (Conciudadanía, 2008). Por su parte, la aproximación del Programa por la Paz del Cinep en relación con el tema de reconciliación puso énfasis en las víctimas, pues "parte de una opción preferencial por aquéllos que han sufrido las consecuencias directas de la guerra” (Villa, Sánchez \& Téllez, 2007, p. 11).

En consonancia con la postura de AMOR, Aproviaci se ha mostrado renuente a asumir la reconciliación entendida como el acercamiento entre víctimas y victimarios. De hecho, ambas organizaciones acordaron trabajar la reconciliación entre las comunidades, "reconstruyendo los lazos rotos por la guerra y promoviendo un proceso de perdón y sanación pero desde las mismas víctimas" (Mujer miembro de Aproviaci, comunicación personal, Mayo 2012). Estas organizaciones no descartan que en un futuro se pueda dar una reconciliación entre víctimas y victimarios cuando existan las condiciones requeridas.

Por su parte, el municipio de San Carlos le apostó al proceso de reconciliación entre víctimas y victimarios, lo que desembocó en la ruptura entre el proceso impulsado desde el CARE en este municipio y Aproviaci en 2009. De acuerdo con un miembro del CARE, la reconciliación en San Carlos se ha asociado fundamentalmente con la posibilidad de lograr una convivencia entre víctimas y victimarios, y de aceptar a estos últimos en la comunidad siempre y cuando se 
comprometan a no incurrir en las atrocidades del pasado (Mujer miembro del CARE, comunicación personal, mayo 2012). Este proceso ha contado con el apoyo de las administraciones locales de este municipio y de otras instituciones del nivel departamental e incluso, nacional.

En contraste, la postura asumida por Aproviaci ha generado tensiones con instituciones del nivel nacional y departamental, que han buscado promover procesos de reconciliación en la región y el trabajo entre víctimas y desmovilizados. Una de las mujeres entrevistadas perteneciente a la junta directiva de Aproviaci se refiere al encuentro entre víctimas y victimarios promovidos por las instituciones y por Conciudadanía en los siguientes términos:

Estaban víctimas y victimarios en el mismo espacio, las víctimas ya no hablaban con confianza, esos espacios que eran tan importantes para las víctimas se habían convertido en otra cosa [...] sentíamos que de parte del gobierno local había un direccionamiento para que la organización de víctimas se casara con eso, porque como estamos en justicia transicional tendemos a que ya nos tenemos que reconciliar y nosotras sabemos que es importante, no hemos dicho que estamos en contra de eso, pero qué significa reconciliación, cómo se entiende y cuál es la responsabilidad frente a ese tema de la reconciliación (Mujer miembro de la junta directiva de Aproviaci, comunicación personal, mayo 2012).

\subsection{Procesos organizativos y acciones para incidir en los espacios de decisión pública}

Un aspecto común de los procesos organizativos seguidos por AMOR, Aproviaci y el CARE es que han buscado encontrar apoyos e interactuar con las instituciones y la esfera política formal como una estrategia para que sus voces sean escuchadas y para posicionar sus reivindicaciones en el ámbito de lo público. Por otro lado, esta pareciera también una estrategia que ha sido importante para sobrevivir en un escenario que no deja de representar una amenaza para la seguridad de los miembros de las organizaciones. Aunque en el 
Oriente Antioqueño los índices de violencia disminuyeron drásticamente después de la desmovilización de los grupos paramilitares, esto no significa que las manifestaciones de violencia en esta región del país hayan desaparecido por completo o que no existan amenazas asociadas a la presencia de actores armados, como manifestaron algunas de las entrevistadas.

AMOR, Aproviaci y el CARE en su interacción con las instituciones y la arena política formal han adoptado distintas estrategias en aras de posicionar sus voces, reivindicaciones en la arena pública y más específicamente incidir en los espacios de decisión pública. En el caso de AMOR esto se planteó como un elemento fundamental desde muy temprano, debido a que entre las metas de la organización estaba la formación política y ciudadana de las mujeres, fundamental para posibilitar su participación y visibilización en el ámbito de lo público. En los últimos años AMOR le ha dado continuidad a este trabajo, a través de la escuela de formación de incidencia política, con la que se espera seguir avanzando en la formación de las mujeres para incidir políticamente.

Por otro lado, se ha buscado avanzar en la construcción de agendas ciudadanas. Para esto AMOR construye su propia agenda, que luego es concertada con los candidatos a alcaldías y concejos. Así mismo, las mujeres de la organización han intentado llegar a los espacios de representación, aunque este último ha sido un proceso difícil; a pesar de que se ha logrado que algunas mujeres de la organización hayan accedido a los concejos, la percepción que se tiene es que estos espacios están vetados para las mujeres y que es muy difícil trabajar en escenarios dominados fundamentalmente por hombres (Mujer miembro de AMOR, comunicación personal, agosto de 2011). De manera más reciente, la apuesta ha sido incidir en la construcción de políticas públicas con enfoque de género en lo local.

En el caso de Aproviaci la incidencia política también ha constituido un factor fundamental. Esta organización ha venido construyendo unas agendas regionales y haciendo propuestas para incidir en los planes de gobierno a nivel municipal. En los últimos años ha promovido 
encuentros de las víctimas con los candidatos a concejos y alcaldías y se han examinado los planes de gobierno y desarrollo, en aras de determinar cuáles de ellos resultan más convenientes para los intereses de las víctimas.

En el caso del CARE los vínculos con la arena política formal han sido incluso más directos. Como habíamos mencionado, el Centro de Acercamiento para la Reconciliación y Reparación se crea por política pública después de la convocatoria de un cabildo abierto en el municipio; por otro lado, varios de los proyectos desarrollados por el CARE han contado directamente con el apoyo de la administración municipal. Esto ha sido posible en buena medida debido al liderazgo de la concejala que ha impulsado estos procesos, quien no solo es la cabeza del CARE, sino que ha sido elegida concejala del municipio durante varios periodos. Esta líder, con el apoyo de diversos sectores de la comunidad, logró desde allí posicionar no solo el tema de víctimas en el municipio, sino impulsar diversos proyectos que han sido fundamentales para el trabajo con las víctimas y los desmovilizados, así como para el proceso de construcción de la memoria.

\section{Conclusiones}

Este artículo se propuso examinar de qué manera los procesos organizativos de víctimas y de mujeres en el Oriente Antioqueño se relacionan con los discursos y expresiones de la democracia local. En lugar de partir de una noción preconcebida de democracia, privilegiamos los discursos y significados que sobre la misma enuncian los actores estudiados. El énfasis en los significados que asume la democracia para los actores que participan en su construcción, nos permite centrarnos en la manera como la democracia se manifiesta en el nivel micro, cómo se construye desde abajo y es conceptualizada por los actores que participan en ella. Este aspecto cobra particular relevancia en esta investigación si se considera que estos procesos organizativos han tenido lugar en un contexto profundamente afectado por el conflicto armado y diversas formas de violencia que podrían 
cuestionar la existencia de la democracia misma desde definiciones más formales o normativas.

El documento se centró específicamente en los procesos organizativos seguidos por la Asociación Provincial de Víctimas a Ciudadanas, el Centro de Acercamiento para la Reconciliación y la Reparación (CARE) y la Asociación de Mujeres del Oriente Antioqueño (AMOR). Con base en las entrevistas y el material recopilado, y tomando como punto de partida los significados que la democracia asume para los actores estudiados, el documento muestra que las relaciones entre los procesos organizativos de víctimas y mujeres en el Oriente Antioqueño y la democracia local pueden ser analizadas fundamentalmente en dos direcciones.

En primer lugar, estas organizaciones han apropiado y redefinido los discursos institucionales sobre la ciudadanía y la participación, y han buscado interactuar con las instituciones en la arena política formal con el propósito de ser escuchadas y posicionar sus reivindicaciones. Estas organizaciones reconocen esta dimensión como un aspecto importante de la democracia. Los programas de formación en ciudadanía y participación política impulsados en la región e inspirados en la Constitución de 1991, han jugado un papel importante en promover y construir el vínculo de estos procesos organizativos con las instituciones y en la apropiación de los discursos institucionales de la democracia. Sin embargo, la construcción de estas relaciones con la democracia también debe entenderse a la luz del proceso organizativo de largo aliento de las mujeres que ha tenido lugar en el Oriente Antioqueño, y cuyos antecedentes pueden rastrearse incluso antes de la Constitución de 1991 y mucho antes que se diera el escalamiento del conflicto armado en la región.

Por otro lado, estas relaciones con las instituciones no han estado libres de tensiones, como es evidenciado en los discursos sobre la reconciliación asumidos por las organizaciones de víctimas y mujeres, por las ONG que han acompañado estos procesos, así como por instituciones del nivel local y nacional que han operado en el territorio. 
En segundo lugar, este artículo muestra que la relación de los procesos organizativos de víctimas y mujeres con la democracia también involucra una apropiación y redefinición de los discursos de ciudadanía y de participación, en aras de incidir y transformar su cotidianidad en un contexto que ha sido fuertemente afectado por la violencia política. En el contexto de los efectos del conflicto armado, la democracia y, específicamente, la ciudadanía y la participación, adquieren un significado para las organizaciones de víctimas y mujeres que está estrechamente asociado con la posibilidad de transformar su cotidianidad, y, en particular, de resistir, responder y actuar sobre los efectos de la guerra en sus vidas y las de sus comunidades. Aproviaci, el CARE y AMOR han promovido y trabajado en procesos de construcción de memoria, de reconstrucción del tejido social y de reconciliación, así como en la organización de las víctimas y las mujeres. Desde este trabajo, las organizaciones de víctimas y mujeres buscan transformar sus experiencias de vida y la cotidianidad en el contexto de los efectos del conflicto armado. De igual manera, la participación en los procesos organizativos de víctimas y de mujeres ha tenido implicaciones importantes para sus miembros, especialmente las mujeres, en términos de posibilitar el cuestionamiento y redefinición de sus relaciones en el ámbito de lo doméstico frecuentemente dominadas por el machismo y los roles femeninos tradicionales.

Así mismo, es importante mencionar que desde esta segunda mirada, la democracia participativa y desde abajo juega un papel central, pero no apunta necesariamente a la interlocución de las organizaciones de víctimas y mujeres con las instituciones o la esfera política formal, sino que está ligado a su capacidad para responder colectivamente a los efectos de la guerra en sus vidas y a la reconstrucción del tejido social. Las movilizaciones, las jornadas de la luz, las trochas por la vida y el trabajo desarrollado por las Provísames son un claro ejemplo del significado que adquiere la democracia en lo local, y más específicamente la ciudadanía y la participación, para estas organizaciones.

En definitiva, es importante mencionar que los significados que la democracia, la participación y la ciudadanía han asumido en esta región para los miembros de los procesos organizativos de víctimas y 
mujeres están fuertemente asociados al contexto de los efectos del conflicto armado sobre las experiencias de vida y la cotidianidad de los miembros de estas organizaciones y las comunidades, así como al proceso de reconstrucción que ha tenido lugar en los últimos años. Si bien es cierto que estas organizaciones han apropiado los discursos de participación y de ciudadanía incorporados por la Constitución de 1991, estos adquieren un significado particular en el contexto de los efectos del conflicto armado y la violencia.

Las Provísames son un ejemplo en esta dirección. Mientras los programas iniciales de formación política y ciudadana estuvieron más enfocados en el liderazgo social y político de las mujeres y en su participación en los espacios públicos, el Programa de las Provísames se enfoca más en el liderazgo y los procesos comunitarios, en lo social. Desde esta perspectiva, la participación y la ciudadanía siguen siendo centrales, pero se entienden de una forma más amplia. El espacio de los abrazos es en sí mismo un espacio de participación donde el interlocutor directo no son las instituciones o los espacios de representación, sino diversos actores sociales, y en el que las experiencias de vida de hombres y mujeres en el contexto de la guerra y su cotidianidad juegan un papel central. Lo mismo puede decirse con respecto a las movilizaciones sociales, las jornadas de la luz y los actos simbólicos de rechazo a la guerra que han tenido lugar en esta región.

\section{Referencias}

Albert, V. (2016). The Limits to Citizen Power: Participatory Democracy and the Entanglements of the State. London: Pluto Press.

Arias, E., \& Goldstein, D. (2010). Violent Pluralism. Understanding the New Democracies of Latin America. En E. Arias \& D. Goldstein (Eds.), Violent Democracies in Latin America (pp. 1-34). Durham y Londres : Duke University Press.

Cinep, Conciudadanía \& AMOR (2007). Entre Pasos y Abrazos. Las promotoras de vida y salud mental, Provísame, se transforman y reconstruyen el tejido social del oriente antioqueño: sistematización de la experiencia del modelo formativo 2004-2006. VGS Ltda. 
Conciudadanía (septiempre, 2008). Reconciliación, si no es ahora, ¿cuándo? Memorias Seminario Internacional Reconciliación y Construcción de Confianza Cívica desde lo Local, Medellín, Colombia.

Coronil, F. (1997). The Magical State: Nature, Money, and Modernity in Venezuela. Chicago: University Chicago Press.

Corporación Vida, Justicia y Paz. (2011). La Paz una construcción de todos los dias. 1988-2011. Rionegro: Corporación Vida, Justicia y Paz.

Delgado, M. (2011). Las víctimas como sujetos politicos en el proceso de justicia y paz en Colombia: discursos imperantes y disruptivos en torno a la reconciliación, la verdad, la justicia y la reparación. (Tesis doctoral, FLACSO, México).

García C., \& Aramburo C. (Eds) (2011). Geografías de la guerra, el poder y la resistencia. Oriente y Urabá antioqueños 1990-2008. Medellín: Instituto de Estudios Regionales (Iner), Universidad de Antioquia.

Grupo de Memoria Histórica GMH. (2009). Memorias en Tiempo de Guerra. Repertorio de Iniciativas. Bogotá: Punto aparte editores.

Grupo de Memoria Histórica GMH. (2011). San Carlos. Memorias del Éxodo en la Guerra. Informe del Grupo de Memoria Histórica de la Comisión De Reparación y Reconciliación CNRR. Bogotá: Taurus.

Novoa, E. (2009). Luchas civicas, trayectorias geopoliticas en Colombia: Movimiento Civico del Oriente Antioqueño, Movimiento Popular Los Inconformes y Comité de Integración del Macižo Colombiano CIMA. Bogotá: Universidad Nacional de Colombia.

Londoño, N., Marín, T., \& Alzate, G. (2005). Una Fuerza Multicolor Organización y Participación de Mujeres A.M.O.R. Bogotá: Alberdania.

Nieto, A. (2014). Resignificando la casita del terror: el espacio como representación de la reconciliación. En N. Martínez, P. Acosta, M. Alfonso, R. Caicedo, R., A. Tabares, S. Ruiz \& Nieto, A. Narrativas de memorias y resistencias (pp. 229-255). Bogotá: Uniminuto.

Observatorio del Programa Presidencial de Derechos Humanos y DIH (2004). Panorama Actual del Oriente Antioqueño. Bogotá: Vicepresidencia de la República.

Ong, A. (1999). Flexible Citizenship: The Cultural Logics of Transnationality. Durham: Duke University Press.

Osorio Campuzano, R. (2013). Paramilitarismo y vida cotidiana en San Carlos (Antioquia): etnografía desde una antropología de la violencia. Boletín de Antropología, 28(45), 130-153. 
Paley, J. (2002). Toward an Anthropology of Democracy. Annual Review of Anthropology, 31, 465-496.

Paley, J. (2008). Introduction. En J. Paley (Ed.). Democracy Anthropological Approaches (pp. 3-20). New Mexico: School for Advanced Research Press.

Peralta, L. (2009). San Carlos: una aproximación a los derechos de las víctimas desde lo local. (Tesis de Maestría en Antropología, Universidad de los Andes, Bogotá)..

Ramírez, M. C. (2010). Maintaining Democracy in Colombia through Political Exclusion, States of Exception, Counterinsurgency, and Dirty War. En E. Arias y D. Goldstein (Eds.), Violent Democracies in Latin America (pp. 84-107). Durham y Londres: Duke University Press.

Restrepo, G. (2010). Memoria e historia de la violencia en los municipios de San Carlos y Apartadó 1980-2005. (Tesis de Maestría en Historia, Universidad de los Andes, Bogotá).

Roldan, M. (2010). End of Discussion Violence, Participatory Democracy, and the Limits of Dissent in Colombia. En E. Arias y D. Goldstein (Eds.), Violent Democracies in Latin America (pp. 63-83). Durham y Londres: Duke University Press.

Verdery, K. (1996). What Was Socialism, and What Comes Next? Princeton: Princeton University Press.

Villa, J., Tejada, C., Sánchez, N., \& Téllez, A. (2007). Nombrar lo Innombrable. Reconciliación Desde la Perspectiva de las Victimas. Bogotá: Programa por la Paz- CINEP. 